\title{
O Plano de Aula para Educação On-line na Pandemia de Covid-19
}

The on-line Education Lesson Plan in the Covid-19 Pandemic

\section{Telma Brito Rocha}

Universidade Federal da Bahia Endereço: Av. Reitor Miguel Calmon, s/n - Canela, Salvador - BA telmabr@ufba.br

\section{(c) (1)}

Recebido 14/04/2021

Aceito 11/05/2021

Publicado 12/05/2021

\section{Resumo}

A pandemia do SARS-CoV-2, que provoca a Covid-19, tem afetado os ordenamentos sociais, políticos e econômicos do país. O distanciamento social, necessário para conter o avanço do vírus, resultou no fechamento de instituições educacionais, e o ensino presencial foi transposto para ambientes virtuais de aprendizagem, onde passou a ser executado exclusivamente com mediação tecnológica. Assim, o presente artigo tem como objetivo apresentar um plano de aula para educação on-line, no componente curricular Didática, utilizado como proposta orientadora para formação de professores (as), no Curso de Licenciatura em Pedagogia de uma universidade pública. De acordo com a atual conjuntura educacional no país, a ação de planejar a aula não pode ser uma mera transposição do presencial, é preciso conhecer o nível de inclusão digital dos discentes, características e potencialidades do ambiente virtual de aprendizagem escolhido. Além disso, ainda apresenta as concepções sobre ensino remoto, educação a distância, educação on-line, ensino híbrido. A abordagem metodológica é qualitativa, na qual utilizaram-se a revisão de literatura e a pesquisa-formação, propondo uma reflexão e ação na formação inicial de professores (as). Resultados, sugere-se a utilização do Moodle (Modular Object-oriented Dynamic Learning Environment) e suas interfaces de atividades, visto que é uma plataforma educacional livre, de código aberto, com possibilidade de uso em atividades síncrona e/ou assíncrona, e, apresentação de um quadro orientador para as etapas de construção do plano de aula, seleção dos conteúdos, objetivo geral e específicos, estratégias metodológicas, definição dos objetos de aprendizagem e a avaliação da aprendizagem.

Palavras-chave: Covid-19. Educação on-line. Plano de aula. Moodle.
COMO CITAR ESTE ARTIGO

ABNT: ROCHA, T. B. O Plano de Aula para Educação On-line na Pandemia de Covid-19. EaD em Foco, v. 11, n. 2, e1460, 2021. doi: https://doi.org/10.18264/eadf.v11i2.1460 


\title{
The on-line Education Lesson Plan in the Covid-19 Pandemic
}

\begin{abstract}
The SARS-CoV-2 pandemic, which causes Covid-19, has affected the country's social, political and economic order. The social distance, necessary to contain the spread of the virus, which resulted in the closure of educational institutions, and face-to-face teaching was transposed to virtual learning environments, where it started to be taught exclusively with technological mediation. Thus, this article aims to present a lesson plan for online education, in the Didactic curricular component, used as a guiding proposal for teacher training, in the Pedagogy Degree Course of a public university. According to the current educational situation in the country, the action of planning the class cannot be a mere transposition of the presence, it is necessary to know the level of digital inclusion of the students, characteristics and potential of the chosen virtual learning environment. In addition, it also presents the concepts of remote education, distance education, online education, hybrid education. The methodological approach is qualitative, in which it uses a literature review and research-training, proposing a reflection and action in the initial training of teachers. Results, it is necessary to use Moodle (Modular Object-oriented Dynamic Learning Environment) and its activity interfaces, since it is a free educational platform, open source, with the possibility of use in synchronous and/or asynchronous activities, and, presentation of a guiding framework for the stages of the construction of the lesson plan, selection of contents, general and specific objectives, methodological strategies, definition of learning objects and the assessment of learning.
\end{abstract}

Keywords: Covid-19. on-line education. Class plan. Moodle.

\section{Introdução}

O mundo vive uma pandemia, que não somente afeta a saúde - sobretudo pública -, como também os ordenamentos econômicos e sociais. O vírus responsável por essa pandemia é o SARS-CoV-2 que causa a Covid-19, uma doença sistêmica, que provoca síndrome respiratória aguda, distúrbios gastrointestinais, hepáticos, cardiovasculares e neurológicos - conforme informação divulgada no site da Organização Mundial da Saúde.

Desde março de 2020 e contrariando as orientações do Governo Federal, alguns governadores e prefeitos no Brasil estabeleceram planos e protocolos de distanciamento e isolamento social a fim de conter o avanço da pandemia. Em alguns lugares, atividades consideradas não essenciais e, sobretudo, que ocorrem em grupos de pessoas - a exemplo das atividades escolares - foram suspensas como medida preventiva.

Nesse cenário, instaurou-se uma urgência no Sistema Educacional Brasileiro. A educação presencial passou a ser on-line, na qual as instituições de ensino, públicas e privadas, docentes e discentes, viram-se comprometidos em adaptar-se a este modelo sem tempo hábil, muitas vezes sem investimentos formativos por parte da instituição em que atuam. 
Com os ambientes virtuais de aprendizagem (AVA) tornando-se as novas salas de aulas, os planejamentos da prática docente, assim como “[...] as ações didáticas e pedagógicas da escola e das instituições de ensino [...]" precisam ser repensados para educação on-line. (FARIAS et.al., 2011, p. 107) Sendo a didática um campo que investiga os fundamentos, as condições e os modos de realizar a educação, carece compreender o planejamento do ensino nesta modalidade de ensino.

Estruturados pelas tecnologias digitais, os discentes hoje reelaboram suas formas de se relacionar com o tempo e espaço, criando novas maneiras de socialização em rede. A educação on-line pode contribuir para transformar o modo massivo do ensino remoto, promovendo mais interação entre docentes e discentes.

Nesse sentido, se faz necessário discutir as diferenças conceituais sobre ensino remoto, Educação à Distância, educação on-line, ensino híbrido para compreender as concepções de planejamento. Além disso, é preciso demonstrar o potencial do (AVA) Moodle para estimular que docentes usem as interfaces de atividades promovendo mais autonomia na construção do trabalho formativo.

Para que ocorra a educação on-line, faz-se necessário estabelecer planejamentos pedagógicos alinhados com o ambiente em que a prática educativa ocorrerá. Isto é, transpor o cronograma e organização do presencial para o on-line é fazer ensino remoto. A educação on-line exige um planejamento específico, com metodologia e avaliação da aprendizagem que estejam em alinhamento com esta modalidade de ensino, bem como, no contexto da pandemia, conhecer as condições de acesso à internet dos discentes para definir a plataforma de gestão do ensino e aprendizagem.

Neste sentido, o presente artigo tem como objetivo apresentar uma proposta orientadora de plano de aula para educação on-line, no contexto da pandemia, com uso do Moodle, elaborada para formação de professores (a) na Licenciatura em Pedagogia da Universidade Federal da Bahia.

\section{Abordagem Metodológica}

A abordagem deste trabalho se situa numa metodologia qualitativa, baseada na pesquisa-formação, com revisão de literatura para comprovar e argumentar com a máxima profundidade as perspectivas levantadas, assumindo um rigor indispensável ao objetivo que se deseja alcançar.

Para Macedo e Guerra (2018), a pesquisa-formação deve ser interventiva e atenta às subjetividades, sensibilidades e comunicabilidades dos indivíduos envolvidos. Trata-se de um método pautado na "[...] formação com a diferença como fundante para legitimar/mobilizar as experiências dos sujeitos socioculturais, via narrativas [...]" para ensino presencial ou online. (MACEDO; GUERRA, 2018, p. 48)

Consoante com a pesquisa-formação foi desenvolvida uma proposta para elaboração de planos de aula, no componente curricular EDC 284 - Didática, do qual sou docente no curso de Licenciatura em Pedagogia da Faculdade de Educação (FACED), da Universidade Federal da Bahia (UFBA), durante o Semestre Letivo Suplementar (SLS), nomenclatura denominada pela Resolução $n^{\circ}$ 01/2020, para o ensino na pandemia de Covid-19 durante o segundo semestre de 2020.

Assim, surge o seguinte problema: como os futuros (as) licenciandos (as) do curso de Pedagogia podem construir planos de aula para educação on-line utilizando o Moodle no contexto do ensino na pandemia?

Para responder à questão, foi elaborada uma proposta de plano de aula para educação on-line, com objetivos, metodologia e concepções de avaliação da aprendizagem, alinhadas com o ensino para esta modalidade, bem como, a apresentação do potencial didático pedagógico do Moodle para considerar as condições de acesso a internet dos discentes na definição de atividades síncronas e assíncronas. 
A escolha do Moodle para utilização no plano de aula se justifica por trata-se de uma plataforma educacional livre, de código aberto, com possibilidade de uso síncrona e/ou assíncrona e por possuir diferentes atividades podendo, então, ser utilizada como interfaces de avaliação o que garante “[...] variadas configurações de ensino e aprendizagem [...]" e o reconhecimento de uma "[...] pluralidade de contextos e as possibilidades educacionais [...]." (AMIEL, 2012, p.19)

\title{
3. Educação com Mediação Tecnológica
}

No ano de 2020, diante da pandemia de COVID-19, docentes, seja da Educação Básica ou superior, da educação pública ou privada do país, foram convocados ao trabalho pedagógico denominado ensino remoto ou ensino não presencial. Compreender as concepções de educação no contexto da mediação tecnológica é fundamental para o planejamento do ensino. Segundo Santos (2020, p. 4), ensino remoto é caracterizado por

[...] mediações audiovisuais das modernas plataformas de web conferência. Muitas delas equipadas com outras interfaces que permitem projetar conteúdos, anotar digitalmente nos materiais, dialogar com chats acoplados numa mesma plataforma. Assim, os professores encontram seus alunos no dia e hora da agenda presencial, só que agora com mediação digital. O ciberespaço é subutilizado como lugar de encontro, cabendo ao recurso assíncrono apenas o acesso a conteúdos e material de estudo da disciplina. Alguns docentes abrem discos virtuais nas nuvens, outros postam em plataformas diversas. Mas ninguém conversa com ninguém fora da hora marcada.

Como podemos observar, ensino remoto não é Educação a Distância (EaD), muito menos Educação on-line, que surgiu a partir dos movimentos próprios da cibercultura e não como uma evolução ou uma nova geração da EaD. A cibercultura tem possibilitado novas formas de socialização e de aprendizagem motivadas pela capacidade comunicacional da Web 2.0. Esses ambientes são formados por um conjunto de interfaces de comunicação síncronas e assíncronas, que utilizam conteúdos em diferentes formatos e linguagens. Essas novas formas para aprender fazem uso de dinâmicas hipertextuais e interativas. Santos (2020, p. 2) afirma:

\begin{abstract}
Se para nós educação online é fenômeno da cibercultura, devemos investir na linguagem hipermídia. Postar apenas textos em pdf, apresentações de slides lineares, videoaulas e ou pirotecnias descontextualizadas é subutilização do digital em rede e instrucionismo curricular. Precisamos engendrar uma teia complexa de conexões e acionar os estudantes a adentrarem os conteúdos, produzindo colaborativamente conhecimentos nas interfaces de comunicação síncronas e assíncronas. Só assim, teremos educação online.
\end{abstract}

Observa-se uma transposição do modelo de comunicação recorrente em situação de ensino e aprendizagem presencial, a transmissão preponderante do docente, currículo fragmentado por componentes, com hora aula para cada um deles, quando a internet tem outra temporalidade. Alves (2020, p. 361) afirma que:

[...] as práticas docentes que vêm sendo realizadas reproduzem o que tem de pior nas aulas presenciais, utilizando um modelo de interação 
broadcasting, no qual os professores transmitem informações e orientações para um grupo de alunos que nem sempre consegue acompanhar o que está acontecendo nesses encontros virtuais e participar. Esse é um clássico exemplo de uma perspectiva instrumental da tecnologia.

Outro conceito que envolve a mediação tecnológica na educação é o ensino híbrido, cuja combinação do presencial e a distância converge em práticas educativas realizadas em espaços virtuais on-line e espaços físicos off-line. Acrescenta-se ainda a combinação de metodologias ativas, novas formulações curriculares e diversidade de recursos tecnológicos. Para alguns autores(as), é possível considerar que o termo aprendizagem híbrida seja coerente com os conceitos descritos anteriormente porque

[...] tomam parte dos aspectos metodológicos e didáticos de uma situação educacional; possibilitam flexibilizar o currículo escolar; propiciam estratégias diversas para o professor em sua práxis pedagógica, como ainda o estudante tem a prerrogativa de personalizar seu aprendizado em consonância com suas preferências e ritmos de estudo. (ABUTAKKA; SILVA; ANJOS, 2019, p. 217)

Na educação mediada por meio de tecnologias se faz necessário selecionar a plataforma de gestão do processo de ensino aprendizagem de acordo com a modalidade escolhida. Aqui, as interfaces de atividades no Moodle (figura 1) são sugeridas para proposição de planos de aula no componente EDC -284 Didática.

Figura 1: Interfaces de Atividades (Moodle)

\begin{tabular}{|c|c|c|c|c|}
\hline 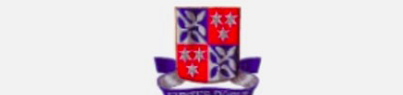 & 令 Início & Eventos & Fv Meus Cursos & minte curso \\
\hline $\begin{array}{l}\text { Licenciatura em Pedagogia } \\
\text { UNIVERSIDADE FEDERAL DA BAHIA }\end{array}$ & EDC284 & DIDÁn & & \\
\hline ATIVIDADES & & $\bigcirc$ 酎 Jogo- Forca & & \\
\hline 0 Ativdade Hot Potatoes & & ○ Jogo - Milionário & & \\
\hline O 量 Base de dados & & 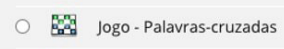 & & \\
\hline $\begin{array}{l}O \text { BiglueButtonBN } \\
0 \text { Chat }\end{array}$ & & ○ Laboratório de Avaliaçăo & & \\
\hline ○) Checklist & & ○ 黒尚 Liçăo & & \\
\hline ० [ Diário & & II Pacote SCORM & & \\
\hline O : Escolha & & $\circ$ I Pesquisa & & \\
\hline 0 Ferramenta externa & & ○ - Illin Pesquisa de avaliaçăo & & \\
\hline ○ 昌 Forrum & & $\circ \searrow$ Questionário & & \\
\hline 0 GeoGebra & & $\circ$ Tarefa & & \\
\hline Glogsario & & ○ 蹈 Wiki & & \\
\hline
\end{tabular}

Fonte: Moodle (UFBA)

Assim, foi utilizado o Moodle por entender que a versão da UFBA oferece vinte e três interfaces de atividades síncronas assíncronas, o que proporciona diversidade no contexto de aprendizagem. Entende-se por atividades síncronas, aquelas que ocorrem com docentes e discentes conectados ao mesmo tempo no mesmo ambiente, portanto, condicionam "[...] a interação a um tempo (cronos) ao vivo, o tempo real". (SANTOS, 2020, p. 2) Já as atividades assíncronas

[...] são aquelas que contam com a dispersão geográfica e a partilha de tempos de comunicação variados. Um interlocutor deixa uma mensagem e esta pode ser comentada e cocriada por todos e todas em tempos (cronos) e existências variados. 


\section{O Moodle e suas Interfaces de Atividades}

O Moodle, em português, significa ambiente modular de aprendizagem dinâmica orientada a objetos; é um software open-source, ou seja, seu código fonte é aberto. O Moodle está sob a licença GNU General Public License (GPL), que permite adaptá-lo, estendê-lo ou modificá-lo. É uma licença copyleft, onde os trabalhos derivados pela GPL só podem ser distribuídos se utilizarem a mesma licença, isso garante a liberdade de compartilhar e alterar todas as versões de um programa bem como assegurar que continue sendo um software livre.

O Moodle permite que se crie um espaço de aprendizagem social, isso significa que o próprio ou a própria docente desenha no ambiente virtual a proposta de seu curso com autonomia, além disso, promove a aprendizagem colaborativa entre discentes com as interfaces de atividades integradas, permite ainda, acessibilidade aos discentes com necessidades educativas específicas.

Essas possibilidades do Moodle garantem práticas pedagógicas com maior flexibilidade, horizontalidade, uma vez que a comunicação todos com todos é incentivada com colaboração e compartilhamento. Suas interfaces de atividades ainda proporcionam debates, pluralismo de ideias a partir de acesso a diferentes tipos de mídias.

Por isso, o uso de interfaces como meio de comunicação interativa pode gerar novas possibilidades formativas, “[...] novas autorias e gêneros textuais. Com elas é possível integrar várias linguagens (sons, textos e imagens-estáticas e dinâmicas) na tela do computador" (SANTOS, 2019, p. 111).

Várias são as interfaces que possibilitam o desenvolvimento do processo de ensino e aprendizagem do discente na educação on-line. Através de atividades síncronas e assíncronas, podemos obter um acompanhamento sistemático do que se vem aprendendo e produzindo. No Moodle, as comunicações síncronas como chats, promovem discussões interativas, possibilitando a criação de texto entre duas ou mais pessoas simultaneamente. Da mesma forma, o BigBlueButtonBN (BBB), em plataforma para realizar webconferência, com comunicação entre usuários, simultaneamente, por meio de áudio e vídeo.

As comunicações assíncronas, tais como, fórum (um importante recurso do desenvolvimento da aprendizagem, pois corresponde a um espaço permanente de interação-ação-reflexão-transformação do eu e do outro).

O diário pode ser um eixo organizador do trabalho com um grande valor formativo nas diversas modalidades e níveis de ensino. Através dele, o discente demonstra suas produções, onde estarão registradas as suas ações e reflexões. O glossário também pode criar e manter uma lista alfabética de termos e definições.

A tarefa consiste na realização de uma atividade a ser desenvolvida pelo participante de um curso e que pode ser feita no próprio espaço disponibilizado pelo Moodle ou realizada fora da rede e enviada para o Ambiente Virtual de Aprendizagem (AVA).

Já o Wiki é uma interface colaborativa que possibilita a construção coletiva de diferentes tipos de textos por vários autores, usando um navegador de internet. É um importante recurso de construção colaborativa.

Amiel (2012) acredita que usar recursos educacionais abertos na educação on-line e no ensino híbrido fomenta uma cultura de compartilhamento e transparência, o que promove uma perspectiva produtiva do trabalho docente, da mesma forma, os recursos podem ser utilizados e modificados por outros docentes.

Quando o docente planeja sua aula, seleciona recursos, em seguida relaciona o que encontrou de novo com o que já existe em seu acervo (materiais, práticas), isto, por sua vez, já está na memória do seu fazer didático-pedagógico. Para o autor, esse processo relacional é "[...] em si, um processo de criação, porém, ao fazê-lo, certamente são adicionados elementos originais." (AMIEL, 2012, p. 26) 
Desse modo, é fundamental planejar um desenho didático que estabeleça canais de comunicação, interações, cocriações e dinâmicas criativas em rede, utilizando todo o potencial pedagógico oferecido pelo AVA Moodle. Para Santos e Silva (2009):

\begin{abstract}
Além da auto aprendizagem, as interfaces dos ambientes virtuais de aprendizagem (AVA) permitem a interatividade e a aprendizagem colaborativa, ou seja, além de aprender com o material, o participante aprende na dialógica com os outros sujeitos envolvidos - professores, tutores e principalmente com outros cursistas - através de processos de comunicação síncronas e assíncronas (fóruns de discussão, lista, chats, blog, webfólios, entre outros). Isso é revolucionário, inclusive quebra e transforma o conceito de distância. Se bem apropriada por cursistas e professores, a educação online deixa de ser EAD para ser simplesmente EDUCAÇÃO. (p. 111)
\end{abstract}

Nesse sentido, a educação on-line exige organização do trabalho pedagógico, como veremos a seguir, que se concretiza por meio do planejamento com concepções bem definidas das ações didáticas e pedagógicas em um plano de aula.

\title{
5. Planejamento de Aula na Educação on-line
}

Planejamento pedagógico é atividade que projeta e organiza o trabalho docente, envolve saberes curriculares, domínio das teorias de aprendizagem e conhecimento da realidade sobre a qual se promove o ensino. Integram o planejamento pedagógico, o plano de unidade, de curso ou componente curricular, elaborado para um determinado período (ano, ciclo, semestre) e o plano de aula, etapa mais detalhada e delimitada de todo o planejamento pedagógico.

Sobre o plano de aula, Libâneo (2013, p. 267) entende que, “[...] deve resultar num documento escrito que servirá não só para orientar as ações do professor como também para possibilitar constantes revisões e aprimoramentos de ano para ano". A construção de um plano de aula deve desempenhar noções acerca dos conhecimentos e conteúdos a serem abordados, os objetivos, a metodologia a ser aplicada e de que forma será realizada a avaliação da aprendizagem. Contudo,

Os momentos didáticos do desenvolvimento metodológico não são rígidos. Cada momento terá duração de tempo de acordo com o conteúdo, com nível de assimilação dos alunos. Às vezes ocupar-se-á mais tempo com a exposição oral da matéria, em outras, com o estudo da matéria. Outras vezes, ainda, tempo maior pode ser dedicado a exercícios de fixação e consolidação. (LIBÂNEO, 2013, p. 268)

Assim, Libâneo (2013, p. 246) afirma que "o planejamento é um processo de racionalização, organização e coordenação da ação docente, articulando a atividade escolar e a problemática do contexto social". Em relação aos requisitos para o planejamento pedagógico que organiza a ação docente, o autor diz que os principais consistem nos "[...] objetivos e tarefas da escola democrática; as exigências dos planos e programas oficiais; as condições prévias dos alunos para a aprendizagem; os princípios e as condições do processo de transmissão e assimilação ativa dos conteúdos." (p. 250).

Realizar um diagnóstico sociodigital dos discentes e tomar conhecimento da realidade em que vai atuar é um dos primeiros passos do processo. Depois que tomamos conhecimento da realidade, é hora de 
estruturar o trabalho pedagógico, através dos elementos que compõem o processo de ensino e aprendizagem, apresentados no plano de aula. Em conformidade, Vasconcelos (2019, p.73) afirma que o planejamento tem algumas exigências que são fundamentais:

[...] vinculação estreita entre análise da realidade (onde estamos?), projeção de finalidades (para onde queremos ir?) e elaboração de formas de mediação/plano de ação(o que fazer para diminuir a distância entre a realidade e a finalidade?)

Consoante com esse diagnóstico inicial, nos planejamentos para a educação on-line é preciso considerar a estrutura tecnológica de docentes e discentes, além do conhecimento das concepções do projeto do curso. Santos e Silva elencam um conjunto de questões orientadoras, a exemplo:

[...] qual o contexto sócio-histórico e cultural dos aprendentes?; quais são seus perfis sociocognitivos e político-cultural?; quais são suas expectativas para o curso online?; qual a infra estrutura tecnológica de que dispõem os docentes e os cursistas?; que competências pretendemos mobilizar nos aprendentes?; que profissionais podem ser agregados ao projeto para uma produção interdisciplinar?; que conteúdos abordar?; como arquitetar o curso nas interfaces de conteúdos e de comunicação?; como estruturar os conteúdos, os objetos e as situações de aprendizagem em hipertexto?; como conciliar situações de aprendizagem individuais (auto-estudo)com situações de aprendizagem interativas (aprendizagem colaborativa)?; como aproveitar as situações de aprendizagem como dispositivos para uma avaliação formativa?; quais indicadores utilizar para avaliar a aprendizagem a partir das participações nas interfaces de comunicação?; que interfaces de conteúdos e de comunicação utilizar em cada aula, fase, bloco, módulo ou unidade do curso? (2009, p. 276).

Outro aspecto a considerar é a relação do plano de aula e a navegabilidade do ambiente virtual de aprendizagem. O visual do site deve refletir a organização apresentada neste plano. A esse respeito, os hipertextos permitem que os discentes realizem percursos de leituras mais plurais e diversificadas. Santos e Silva (2009) acreditam que através dos links:

[...] o leitor adentre espaços e conteúdos e construa seus próprios caminhos de leitura não mais presos à linearidade das páginas e do documento com início, meio e fim, dos limites das margens, nas notas de rodapés. O fim no hipertexto é sempre um novo começo caleidoscópico, no qual, simultaneamente, podemos ler vários textos, cortar, colar e criar intertextos (p. 278).

Para fundamentar a avaliação da aprendizagem num plano de aula para educação on-line, é necessário lançar mão de um referencial crítico; na proposta desenvolvida com discentes da Licenciatura em Pedagogia foi adotada a avaliação formativa e mediadora. Santos e Alves $(2015$, p. 2) definem avaliação formativa como aquela que está "[...] integrando processo de aprendizagem e atua como recurso adequado para regular e adaptar a programação às necessidades e dificuldades dos alunos." Pesce (2012) também considera importante a avaliação formativa em cursos on-line porque seus princípios pautam-se: 
a) em um caráter processual, no qual professor e estudantes são sujeitos ativos no processo de construção de conhecimento;

b) nos centros de interesse, a partir dos temas primordiais a uma dada área; c) na elaboração de objetivos iniciais, a partir do diagnóstico do alunado, levando-se em conta seus anseios e necessidades;

d) no acolhimento dos objetivos oriundos do processo de formação;

e) na avaliação dialogada, que integra a avaliação do desempenho dos estudantes, a autoavaliação de cada um deles e sua avaliação sobre o curso, em distintos momentos da vigência do mesmo;

f) na abordagem diagnóstica, que revê as ações de mediação;

g) na tessitura de um quadro teórico-metodológico contribuinte à formação do aprendiz (p. 197-198).

Sobre o conceito de avaliação mediadora, Hoffmann (2005, p. 58) destaca sua função, dizendo que deve estar a serviço na escola, “[...] da experiência na construção do conhecimento de educandos e educadores". Para a autora, a mediação é a possibilidade de encontro, diálogo, reciprocidade de pensamentos, sentimentos e emoções entre docentes e discentes, “[...] pessoas em processo de humanização - um espaço a ser construído". (HOFFMANN, 2005, p. 9)

Para Hoffmann $(2005$, p.9) é preciso indagar sobre os fatores que favorecem esse encontro, essa aproximação. Nas suas palavras: “[...] eu tenho claro que a relação entre educando e educador se estabelece a partir do ato de conhecer, da necessidade de desvendar o mundo, em torno do objeto do desejo de conhecer."

A avaliação mediadora para a autora ocorre através das relações docente e discente, discente e discente, pelas interações sustentadas em diálogos e por práticas pedagógicas que privilegiam o pensamento autônomo. Logo, expressar, comunicar, mostrar o que se aprendeu nessas relações, seus erros e acertos são caminhos que levam à construção do conhecimento.

Barreiro-Pinto e Silva (2008, p. 4) acreditam que a avaliação mediadora:

[...] preconiza essencialmente o processo, com isso, tem-se a oportunidade de estimular, observar e registrar, as formas de comunicação com as quais obteve maior êxito, bem como detectar aquelas em que apresentou maior dificuldade. Os registros dessa trajetória não têm por finalidade apenas diagnosticar a situação e sim, a partir deles, reestruturar o planejamento, direcionando o trabalho pedagógico para a promoção de tarefas que possam incentivar o aluno a desenvolver estratégias pessoais de superação da dificuldade apresentada.

Os registros da trajetória de aprendizagem dos discentes é um importante recurso para prática avaliativa na educação on-line, tem caráter formativo e pode ocorrer através da construção da atividade diária, por exemplo, uma interface avaliativa no Moodle que permite o acompanhamento do discente. A partir deste diário, ele também pode criar seus registros, e, no mesmo ambiente virtual, acessar outros dados de avaliações individuais e do grupo, combinando dados qualitativos e quantitativos obtidos em outras interfaces avaliativas no mesmo ambiente virtual de aprendizagem durante todo processo.

Segundo Hoffmann (1993, p.118), “ [...] se o professor fizer apenas o registro das notas dos alunos nos trabalhos, ele não saberá descrever, após um tempo, quais dificuldades cada aluno apresentou, o que ele fez para auxiliá-lo a compreender aquele aspecto." Em consonância, Dias Sobrinho (2003, p. 180) afirma 
que a “[...] avaliação é, assim, muito mais crítica, que meramente constatação. Deve analisar o realizado, mas para melhor cumprir o que há por realizar."

A elaboração de um plano de aula depende de algumas etapas. A princípio, é necessário definir o objetivo geral; após, tem-se a definição dos objetivos específicos. Na sequência, definem-se os conteúdos que englobam o conteúdo curricular. Na sessão metodológica, deverão ser apresentadas toda trajetória que será desenvolvida na aula.

Na educação on-line, dialogicidade, compartilhamento, cooperação, problematização, a prática de comunicação horizontalizada (todos com todos), em coautorias, estimuladas pela ação democrática do protagonismo estudantil, são características de uma metodologia mais ativa.

No que concerne à educação on-line, é importante ainda descrever os objetos de aprendizagem, os recursos educacionais abertos, neste caso o Moodle e as interfaces de atividades. Também deverá ser apresentado no plano de aula de que maneira os conteúdos abordados serão avaliados. Isto é, descrição das abordagens que serão adotadas (qualitativa e/ou quantitativa) bem como as concepções formativa e mediadora.

Por fim, deve possuir as referências das obras utilizadas (impresso ou digital) consultadas, conforme quadro a seguir dos elementos que compõem o plano de aula (quadro 1).

Quadro 1

Etapas para Composição do Plano de Aula

CURSO:

COMPONENTE CURRICULAR:

DOCENTE:

MODALIDADE: EDUCAÇÃO ON-LINE

DURAÇÃO DA AULA:

TOTAL DE DISCENTES:

CONTEÚDO CURRICULAR:

OBJETIVO GERAL: projeta o resultado geral do conteúdo curricular desenvolvido na aula.

OBJETIVOS ESPECÍFICOS: detalham em até três itens (recomendado), o que se espera de cada um dos temas que englobam o conteúdo curricular da aula, indicam os propósitos que se pretende observar e atingir. Geralmente, expressam verbos indicativos de construção de habilidades, tais como conhecimento (identificar, definir, associar, comparar, descrever, diferenciar, reconhecer, mostrar, entre outros); aplicação (calcular, demonstrar, estimar, localizar, operar, medir, desenvolver, solucionar); solução de problemas - defender, criar, desenhar, criticar, debater, organizar, propor, classificar).

CONTEÚDO: temas que englobam o conteúdo curricular (descrição dos subtemas que compõem o tema geral da aula). O docente tem autonomia de articular os saberes críticos sociais para realização de uma aprendizagem mais significativa, com autoria e práticas multidisciplinares ou interdisciplinares. 
METODOLOGIA: apresenta as trajetórias traçadas/planejadas que serão vivenciadas pelos docentes e discentes; orientam e direcionam o processo de ensino e aprendizagem em função de certos objetivos ou fins educativos/formativos. Representa a estruturação dos caminhos a serem percorridos pela ação didática. Na educação on-line, dialogicidade, compartilhamento, cooperação, problematização, a prática de comunicação horizontalizada (todos com todos), em coautorias, estimuladas pela ação democrática do protagonismo estudantil, são características de uma metodologia mais ativa. É preciso definir e descrever o tempo de atividades síncronas e assíncronas, os recursos educacionais abertos e/ou fechados. No Moodle as interfaces de atividades síncronas são: BigBlueButtonBN e Chat. Já as interfaces de atividades assíncronas são: Hot Potatoes, Base de Dados, Checklist, Diário, Escolha, Ferramenta Externa, Fórum, Geogebra, Glossário, Caça-palavras, Forca, Milionário, Palavras Cruzadas, Laboratório de Avaliação, Lição, Pacote SCORM, Pesquisa, Pesquisa de Avaliação, Questionário, Tarefa, Wiki. Assim, as atividades síncronas e assíncronas não devem ser dissociadas, elas se complementam numa proposta didática. Além disso, é importante o estímulo à utilização de diferentes mídias (blogs, vídeos, podcasts), aplicativos de simulação em ciências da natureza, matemática, educação museal, e, a seleção dos softwares de acessibilidade para discentes com necessidades educativas específicas. Tomar em consideração as condições de acompanhamento das atividades pelos discentes, o nível de inclusão digital, bem como, ouvir suas sugestões, são também necessários para o desenvolvimento metodológico.

OBJETOS DE APRENDIZAGEM: são recursos educacionais abertos e/ou fechados que serão utilizados no desenvolvimento metodológico. Descrição do ambiente virtual de aprendizagem utilizado, os softwares, aplicativos, e-books (livros digitais). A descrição deve estar de acordo com a proposta metodológica em articulação com os objetivos propostos.

AVALIAÇÃO ON-LINE: descrição das abordagens que serão adotadas (qualitativa e/ou quantitativa). Podem ser desenvolvidas a autoavaliação docente e discente (reflexão sobre conquistas de aprendizagens, dificuldades), avaliação do grupo (das atividades de interfaces quando solicitadas em parcerias, trios ou mais), avaliação individual (atividades realizadas solitariamente). As avaliações no ensino on-line podem abranger as seguintes concepções: mediadora (dialógica/ interpretativa, reflexão prospectiva e reflexão-na-ação); formativa (acompanha e regula a aprendizagem, processual). Aqui devem ser descritas as interfaces de atividades que orientaram o desenvolvimento metodológico descrito nos objetos de aprendizagem. Além disso, o (a) docente deve desenvolver os critérios avaliativos para o conjunto de temas que serão trabalhados no processo de ensino e aprendizagem.

BIBLIOGRAFIA:são todas as obras (impresso ou digital) consultadas para elaboração do plano de aula, bem como outras mídias (vídeos, músicas e podcast).

Para mais, é importante destacar que, mesmo após a consolidação do planejamento docente, este possui caráter assíduo e, logo, poderá ser sempre revisado predizendo o melhor caminho para o aprendizado dos discentes. Elaborar de maneira autoral, objetivos, metodologia, selecionar os objetos de aprendizagem, definir os critérios para avaliação on-line, é uma condição essencial "[...] para refletir sobre a direção do nosso trabalho. Do contrário, ficaremos entregues aos rumos e condições estabelecidas por outros." (FARIAS et al., 2011, p. 112) Assim, o planejamento será organizado democraticamente e comprometido com o ensino e aprendizagem de todos envolvidos no processo. 


\section{Conclusões}

Como se pode notar a partir das discussões apresentadas, para a construção de um planejamento, é importante que os docentes conheçam seus discentes, suas bagagens socioeconômicas e políticas, seu capital cultural, o espaço-tempo em que essas ações educativas serão, efetivamente, postas em prática. É dessa maneira que o planejamento da aula a ser ministrada será organizado democraticamente e comprometido com o ensino e aprendizagem de todos envolvidos no processo.

O planejamento pedagógico em sala de aula não se resume apenas a construir um arquivo de texto, mas sim a organização consciente da prática docente, levando em consideração bagagens e problemáticas políticas, socioeconômicas e culturais, que incluam todos os indivíduos envolvidos no processo de ensino e aprendizagem. O plano de aula apresentado não pretende criar modelos, mas, compartilhar uma proposta de construção para atividades síncronas e assíncronas na educação on-line, seja para o momento da pandemia ou não.

Neste contexto, diante do desenvolvimento das tecnologias digitais e dos dispositivos móveis e o crescente acesso à internet, o Estado e as instituições de ensino precisam atentar-se para a formação de toda comunidade escolar no que concerne o acesso e uso das tecnologias digitais. Sendo assim, com a inclusão digital de docentes e discentes, o futuro aponta, cada vez mais, para o hibridismo entre o presencial e o on-line, de maneira que se percebe essa mudança que atualmente ainda é conjuntural, mas a mesma precisa estar sendo levada em consideração a esses fatores no plano de aula.

\section{Referências}

ABUTAKKA, R. V.; SILVA, L. M.; ANJOS, A. M. dos.Ensino híbrido: organização e sistematização de conceitos com base em revisão sistemática da literatura. EmRede: Revista de Educação a Distância, Porto Alegre, v. 6, n. 2, p. 204-220, 2019. Disponível em: https://www.aunirede.org.br/revista/index.php/ emrede/article/view/467. Acesso em: 10 abr. 2021.

ALVES, L. Educação remota: entre ilusão e a realidade. Interfaces Científicas, Aracaju, v. 8, n. 3, p. 348365, ago. 2020. Disponível em: https://periodicos.set.edu.br/index.php/educacao/article/view/9251. Acesso em: 19 mar. 2021.

AMIEL, T. Educação aberta: configurando ambientes, práticas e recursos educacionais. In: SANTANA, B.; ROSSINI, C.; PRETTO, N. De L. (org.). Recursos educacionais abertos: práticas colaborativas e políticas públicas. Salvador: EDUFBA, 2012. v. 1, p. 17-34. Disponível em: https://www.aberta.org.br/ livrorea/livro/livroREA-1edicao-mai2012.pdf. Acesso em: 16 mar. 2021.

BARREIRO-PINTO, I. A.; SILVA, M. Avaliar a aprendizagem na educação online: a transposição de procedimentos presenciais e a dinâmica específica da web. 2008. Disponível em: http://31 reuniao.anped. org.br/1trabalho/GT16-4700--Int.pdf. Acesso em: 07 abr. 2021.

DIAS SOBRINHO, J. Avaliação: políticas e reformas da educação superior. São Paulo: Cortez, 2003.

FARIAS, I. M. S. et al. Didática e docência: aprendendo a profissão. Brasília, DF: Líber Livros, 2011.

HOFFMANN, J. Avaliação mediadora: uma prática em construção da pré-escola: a universidade. 11. ed. Porto Alegre: Mediação, 1993.

HOFFMANN, J. O jogo do contrário em avaliação. Porto Alegre: Mediação, 2005.

LIBÂNEO, J. C. Didática. 2 ed. São Paulo: Cortez, 2013. 
MACEDO, R. S.; GUERRA, D. M. J. Reflexões sobre a exteriorização das experiências formativas via diários online em contextos multirreferenciais de pesquisa-formação. In: SANTOS,E.; CAPUTO, S. G. Diário de pesquisa na cibercultura: narrativas multirreferenciais com os cotidianos. 1ed. Rio de Janeiro: OMODE, 2018.

PESCE, L. M. Avaliação da aprendizagem nos programas online de formação continuada de educadores. Estudos em Avaliação Educacional, Rio de Janeiro,v. 23, n. 51, p. 190-212, 2012.Disponível em: http://publicacoes.fcc.org.br/ojs/index.php/eae/article/view/1956. Acesso em: 11 abr. 2021.

SANTOS, E. EAD, palavra proibida. Educação online, pouca gente sabe o que é. Ensino remoto, o que temos para hoje. Mas qual é mesmo a diferença? Revista Docência e Cibercultura, Notícias, Rio de Janeiro,22 jun.2020. Disponível em: https://www.e-publicacoes.uerj.br/index.php/re-doc/announcement/view/1119. Acesso em: 12 abr. 2021.

SANTOS, E. Pesquisa-formação na cibercultura. Teresina: EDUFPI, 2019. Disponível em: http://www. edmeasantos.pro.br/assets/livros/Livro\%20PESQUISA-FORMA\%C3\%87\%C3\%830\%20NA\%20 CIBERCULTURA E-BOOK.pdf. Acesso em: 10 jan. 2021.

SANTOS, E.; SILVA, M. Desenho didático interativo para educação online. Revista Iberoamericana de Educación, Madrid, n. 49, p. 267-287, enero-abr., 2009. Disponível em: https://rieoei.org/historico/ documentos/rie49a11.pdf. Acesso em: 08 abr. 2021.

SANTOS, T. J. C. P.; ALVES, M. P. Perspetivas de avaliação das aprendizagens, no ensino básico. Revista de Estudios e Investigaciónen Psicología y Educación, La Coruña, SP, n. 10, p. 69-74, 28 nov. 2015. Disponível em: https://revistas.udc.es/index.php/reipe/article/view/reipe.2015.0.10.437/pdf_268. Acesso em: 07 abr. 2021.

VASCONCELOS, C. Reflexões sobre o planejamento e algumas de suas interfaces com o projeto político-pedagógico e a avaliação. In: D'Ávila, C; MARIN, A. J; FRANCO, M. A. S; FERREIRA, L. G. Didática: saberes estruturantes e formação de professores. Salvador: EDUFBA, 2019. Disponível em: https:// repositorio.ufba.br/ri/handle/ri/30772. Acesso em: 12 ago. 2021. 